Pathophysiology of Haemostasis and Thrombosis

\title{
Contortrostatin, a Snake Venom Disintegrin with Anti-Angiogenic and Anti-Tumor Activity
}

\author{
Stephen Swenson ${ }^{\mathrm{a}}$ Fritz Costa $^{\mathrm{a}}$ William Ernst $^{\mathrm{b}}$ Gary Fujii ${ }^{\mathrm{b}}$ \\ Francis S. Markland ${ }^{\mathrm{a}}$ \\ a University of Southern California, Keck School of Medicine, and ${ }^{b}$ Molecular Express, Inc., Los Angeles, Calif., USA
}

\author{
Key Words \\ Snake venom - Disintegrin - Contortrostatin - Breast \\ cancer · Ovarian cancer · Anti-angiogenesis
}

\begin{abstract}
Disintegrins are soluble peptides found in snake venom. They bind to Arg-Gly-Asp (RGD)-responsive integrins with high affinity ( $\mathrm{n} M$ range) and block integrin function. Contortrostatin (CN), the disintegrin from southern copperhead venom, is a homodimer with a molecular weight of 13,500. Each chain contains 65 amino acids with an Arg-Gly-Asp motif. CN has anti-invasive and anti-adhesive activity on tumor cells and endothelial cells in vitro, and binds to integrins $\alpha \mathrm{v} \beta 3, \alpha \mathrm{v} \beta 5$, and/or $\alpha 5 \beta 1$. In vivo studies using the human metastatic breast cancer cell line MDA-MB-435, in an orthotopic xenograft model in nude mice, revealed that $\mathrm{CN}$ has potent anti-tumor and anti-angiogenic activity. Recent studies have employed an intravenous liposomal delivery procedure. Liposomal delivery of $\mathrm{CN}$ has also been shown to provide effective in vivo anti-tumor and anti-angiogenic activity in a human ovarian cancer animal model.
\end{abstract}

Copyright $(2) 2005$ S. Karger AG, Basel

F.S.M. has declared a financial interest in Pivotal BioSciences, Inc., whose product, contortrostatin, was studied in the work presented in this paper.

\section{KARGER}

(ㄱ) 2005 S. Karger AG, Basel

Fax +41613061234

E-Mail karger@karger.ch

www.karger.com
Accessible online at: www.karger.com/pht

\section{Introduction}

Integrins are $\alpha / \beta$ heterodimeric glycoproteins [1]. The different $\alpha$ subunits combine with distinct $\beta$ subunits resulting in a range of specificities toward various extracellular matrix (ECM) proteins [2]. Several classes of integrins recognize the RGD sequence present in ECM proteins [3], allowing integrins to link cytoskeletal proteins with the ECM and to be involved in bi-directional signaling that alters cellular functions. Among these interactions are the adhesion of both endothelial cells and cancer cells to ECM proteins, interactions that are integral to metastasis and tumor growth. The importance of vitronectin receptors (integrins $\alpha v \beta 3$ and $\alpha v \beta 5$ ) in angiogenesis is well known $[4,5]$. Yet integrins are not only central to angiogenesis. Pathological examination indicates that the level of $\alpha \mathrm{v}$ expression in breast cancer is directly related to migration or metastasis [6], with higher levels of integrin associated with a more metastatic phenotype.

Disintegrins are small, disulfide-rich, Arg-Gly-Asp (RGD)-containing peptides that bind to integrins on the surface of normal and malignant cells [7]. Disintegrins have been characterized from many snake venoms and were originally characterized as platelet aggregation inhibitors [8]. Nuclear magnetic resonance has been used to determine the structures of several disintegrins [9]; they display no secondary structure, but are characterized 
by an RGD sequence at the tip of a flexible loop anchored by disulfide bonds and protruding from the main body of the peptide chain. Contortrostatin $(\mathrm{CN})$ was purified from southern copperhead venom [10], and is a homodimer. It has a molecular mass $(\mathrm{Mr})$ of 13,500 ; each chain has an RGD sequence and an $\mathrm{Mr}$ of 6,700. The $\mathrm{CN}$ gene is part of a precursor composed of pro-protein, metalloproteinase, and disintegrin domains [11]. The disintegrin domain encodes 65 amino acids with a molecular weight equal to that of the $\mathrm{CN}$ subunit. $\mathrm{CN}$ is truncated at its amino-terminus compared to other disintegrins; the missing sequence contains two cysteine residues. All cysteines in other disintegrins are involved in disulfide bonds; since there are two unpartnered cysteine residues in the residual $\mathrm{CN}$ sequence, they must be involved in its dimerization. $\mathrm{CN}$ binds competitively to integrins of the $\beta 1, \beta 3$, and $\beta 5$ subclasses, including integrin receptors for fibronectin $(\alpha 5 \beta 1)$, vitronectin $(\alpha \mathrm{v} \beta 3, \alpha \mathrm{v} \beta 5)$, and fibrinogen $(\alpha \operatorname{IIb} \beta 3)[10,12,13]$. The lack of integrin specificity by $\mathrm{CN}$ is an advantage in controlling cancer growth and dissemination. $\mathrm{CN}$ disrupts angiogenesis induced by both bFGF and VEGF, consistent with the observation that a cyclic RGD peptide had no selectivity among $\alpha \mathrm{v}$ family members [14].

In the present study, we report that $\mathrm{CN}$ can significantly inhibit angiogenesis and tumor progression in vivo, using MDA-MB-435, an $\alpha v \beta 3-, \alpha v \beta 5-, \alpha 5 \beta 1$-positive, human metastatic breast cancer cell line, and $\mathrm{A} 2780^{\mathrm{SEAP}}$, an $\alpha \mathrm{v} \beta 5$-, $\alpha 5 \beta 1$-positive, $\alpha \mathrm{v} \beta 3$-negative, human ovarian cancer cell line. Recently, a recombinant form of $\mathrm{CN}$ has been produced, making clinical translation of this technology a more distinct possibility (see accompanying Chapter by Minea et al., in this volume).

\section{Materials and Methods}

\section{Materials}

Venom of Agkistrodon contortrix contortrix was purchased from the Miami Serpentarium (Punta Gorda, Fla.). CN was purified by multi-step high-performance liquid chromatography (HPLC) according to an established protocol $[10,12]$. Human metastatic mammary cancer cell line MDA-MB-435 was provided by Dr. Janet E. Price, M.D. Anderson Cancer Center, Houston, Tex. Human ovarian cancer cell line A2780 ${ }^{\mathrm{SEAP}}$ was provided by Dr. Thomas C. Hamilton, Fox Chase Cancer Center, Philadelphia, Pa., and the SEAP detection assay kit was purchased from BD Biosciences (Palo Alto, Calif.). The monoclonal antibody (mAb) against CD31 antigen was purchased from Sigma (St. Louis, Mo.) and the immunohistochemistry detection kit was purchased from Zymed Laboratories, Inc. (South San Francisco, Calif.). All other reagents were of the best quality available.

\section{Liposome Preparation}

Liposomes were prepared using different ratios of high transition temperature lipids, cholesterol, and lipids derivatized with long-chain polymers (polyethylene glycol). The particles were formed using probe sonication according to previously described procedures $[15,16]$.

\section{In vivo Efficacy of LCN in an Animal Model of Breast} Cancer

For the efficacy studies, human metastatic breast cancer cells (MDA-MB-435, $5 \times 10^{5}$ cells) were implanted in the mammary fat pads of 5-week-old nude mice. The tumors were allowed to grow until palpable (14 days) at which time $\mathrm{CN}$ administration was initiated as previously described $[16,17]$. In the initial breast cancer efficacy study, five mice per group were used and LCN was administered via three different modes: intravenous (IV) administration every other day $(60 \mu \mathrm{g} / 100 \mu \mathrm{l}$ of LCN per injection), IV administration twice weekly (100 $\mu \mathrm{g} / 100 \mu \mathrm{l}$, LCN per injection) and daily intratumor (IT) administration $(30 \mu \mathrm{g} /$ $100 \mu 1, \mathrm{LCN}$ per injection). Appropriate controls for the different delivery systems were employed. A second experiment with 10 mice per group was used to validate the conclusions from the first study and to gain a more statistically accurate evaluation of the effect of CN and LCN on tumor growth. In this trial, three groups were evaluated: LCN delivered IV twice weekly (100 $\mu \mathrm{g} \mathrm{LCN/in-}$ jection), daily native CN-IT (30 $\mu \mathrm{g} \mathrm{CN} /$ injection), and PBS control.

\section{In vivo Efficacy of LCN in an Animal Model of Ovarian Cancer}

For efficacy studies, human ovarian cancer cells (A2780 ${ }^{\text {SEAP }}$ ) growing as a monolayer in culture were harvested with trypsin EDTA, washed with complete medium, and resuspended in PBS. A2780 ${ }^{\text {SEAP }}$ cells $\left(2 \times 10^{7}\right)$ were suspended in $4 \mathrm{ml}$ PBS and $100 \mu \mathrm{l}$ of the cell suspension was injected intraperitoneally into 40 fiveweek-old female athymic nude mice (Balb/c/nu/nu) weighing approximately $20 \mathrm{~g}$ each (Simonsen Labs, Gilroy, Calif.). Each animal received $5 \times 10^{5}$ cells, and the tumors were allowed to implant for 4 days prior to treatment. The animals were maintained in a pathogen-free condition and received sterilized commercial food and water ad libitum. After 4 days, groups of 10 animals each received either: $30 \mu \mathrm{g}$ daily intraperitoneal (IP) injections of $\mathrm{CN}$ (CN-IP), $105 \mu \mathrm{g}$ twice weekly tail vein injections of LCN (LCN-IV Low), $210 \mu \mathrm{g}$ twice weekly IV injections of LCN (LCN-IV High), or daily IP PBS injections, for 28 days. Peripheral blood $(40 \mu \mathrm{l})$ was obtained by orbital puncture with heparinized capillary glass tubes (VWR, West Chester, Pa.). The blood was then transferred to a microfuge tube, and about $20 \mu$ l of plasma was collected after the blood was centrifuged for $10 \mathrm{~min}$ at a speed of $14,000 \times \mathrm{rpm}$ (14.1 rcf). Plasma was stored at $-20^{\circ} \mathrm{C}$ until SEAP analysis.

\section{SEAP Assay}

A previously described procedure was employed [18]. Two microliter of serum collected from each animal was pipetted to a 96well microtiter plate and incubated in a $60^{\circ} \mathrm{C}$ oven for $30 \mathrm{~min}$. Incubation at high temperatures should denature any endogenous alkaline phosphatase, but will not denature alkaline phosphatase secreted by the tumor cells. After heat treatment, the samples are allowed to cool on ice for $2 \mathrm{~min}$ and then $97 \mu$ l of assay buffer (BD Biosciences, Palo Alto, Calif.) was added to the serum and allowed 
to incubate at room temperature for $5 \mathrm{~min}$. The assay buffer contains L-homoarginine, which inhibited any residual endogenous alkaline phosphatase, but not SEAP. The reaction mixture was then exposed to $3 \mu$ l fluorescent 4-methylumbelliferyl phosphate $(1 \mathrm{mM})$ and incubated in total darkness for $1 \mathrm{~h}$ at RT. Fluorescence was then determined using a CytoFluor 2300 fluorometer (Millipore, Billerica, Mass.) with excitation and emission at 360 and $460 \mathrm{~nm}$, respectively.

Anti-Angiogenic Activity of LCN in Breast and Ovarian Cancer

Since previous in vivo studies with $\mathrm{CN}$ indicated that there was a dramatic inhibitory effect on angiogenesis in growing tumors [19-21], we examined the effect of LCN on tumor angiogenesis in the MDA-MB-435 and A2780 ${ }^{\text {SEAP }}$ models. Tumors from treated and untreated mice in the LCN efficacy studies were fixed in $4 \%$ normal buffered formalin and embedded in paraffin blocks as described [16, 22]. Anti-CD31 (PECAM-1) monoclonal antibody was used for immunohistochemistry. A number of properties of CD31 make it an optimal reporter molecule for determination of tumor angiogenesis [23].

\section{Results}

Contortrostatin Inhibits MDA-MB-435 Mammary

Cancer Growth

MDA-MB-435 cells were implanted in the mammary fat pads of nude mice and the tumors were allowed to grow until palpable (14 days) at which time drug administration was initiated. In the initial study, five mice per group were used and $\mathrm{LCN}$ was administered via three different methods (fig. 1a, left). A second experiment with 10 mice per group employed three groups: $\mathrm{LCN}$ delivered IV twice weekly (100 $\mu \mathrm{g}$ LCN/injection), daily native CNIT (30 $\mu \mathrm{g} \mathrm{CN/injection),} \mathrm{and} \mathrm{PBS} \mathrm{control} \mathrm{(fig.} \mathrm{1a,} \mathrm{right).}$ The results of both studies reveal statistical significance $(\mathrm{p}<0.0001)$ between both treatment groups and control, and the data correlates well with previous observations about tumor growth rates and the effect of $\mathrm{CN}$ on tumor size [17]. Intravenous LCN showed equivalent anti-tumor activity to direct intratumor administration of native $\mathrm{CN}$, regardless of whether $\mathrm{LCN}$ is delivered IV every other day or twice weekly. However, intratumor administration of LCN shows no effect on tumor growth. The reason for this is under study, but we suspect it is related to the site of delivery. Intratumor injection delivers LCN to the necrotic core of the tumor where intratumoral pressure may inhibit release of CN. With LCN-IV, we hypothesize that $\mathrm{CN}$ is slowly released from the deposits of liposomes that accumulate as they leak from the vasculature throughout the tumor. Not only do these experiments reveal a statistically significant difference between intravenous LCN and untreated PBS control, but they also indi- cate that twice weekly intravenous administration of $\mathrm{LCN}$ is as effective as daily intratumor administration of $\mathrm{CN}$, and compared to intratumor delivery, the intravenous method of administration of LCN is directly translatable to the clinic for metastatic breast cancer.

As expected IV delivery of native $\mathrm{CN}$ showed no antitumor efficacy; this was in large part due to the very short circulatory half-life of $\mathrm{CN}$. Thus, these experiments indicate the significant advantage of intravenous delivery of LCN as compared to IV delivery of unencapsulated CN. LCN is available in the circulation for a substantially longer period of time and passively accumulates at the site of the mammary tumor, presumably due to the leakiness of the angiogenic vasculature of the tumor [16].

\section{Anti-Angiogenic Activity of LCN in Breast Cancer}

We examined the effect of LCN on tumor angiogenesis in the MDA-MB-435 model. Tumors from treated and untreated mice in the LrCN and LCN efficacy studies were fixed as described in Materials and Methods. Quantitation of the stained vessels was performed using 'hot spot' analysis [17, 20, 24, 25]. Anti-CD31 (PECAM1) monoclonal antibody was used for immunohistochemistry because it has been reported to be highly expressed on angiogenic vasculature [23]. Figure 1b presents a graph of the quantitation of CD31 immunostaining in the different treatment groups: PBS, LCN-IT (30 $\mu \mathrm{g}$ twice weekly), and LCN-IV (105 $\mu \mathrm{g}$ twice weekly). There is a statistically significant $(\mathrm{p}<0.0001)$ reduction of microvascular density in the LCN group as compared to the PBS control, which corresponds to $\sim 95 \%$ reduction of angiogenesis.

\section{Contortrostatin Inhibits A2780 SEAP Tumor \\ Formation}

Six-week-old female athymic nude mice were injected intraperitoneally with $5 \times 10^{5} \mathrm{~A} 2780^{\mathrm{SEAP}}$ cells and the cells were allowed to implant for 4 days. After 4 days the animals (10 animals per group) were treated with either: PBS, IP native CN, or LCN-IV (at two doses) for 28 days (see Materials and Methods). Thirty-two days after intraperitoneal injection of $\mathrm{A} 2780^{\mathrm{SEAP}}$ cells in nude mice, all animals were euthanized and necroscopy was performed. The peritoneal cavity of each animal was photographed and the occurrence of tumors was noted in the following organs: liver, spleen, kidney, bladder, ovary, stomach, and intestine. Gross examination of the peritoneal cavity shows a dramatic decrease in the numbers and size of tumors formed in the treated animals as compared to the control group (data not shown). Tumors were then col- 


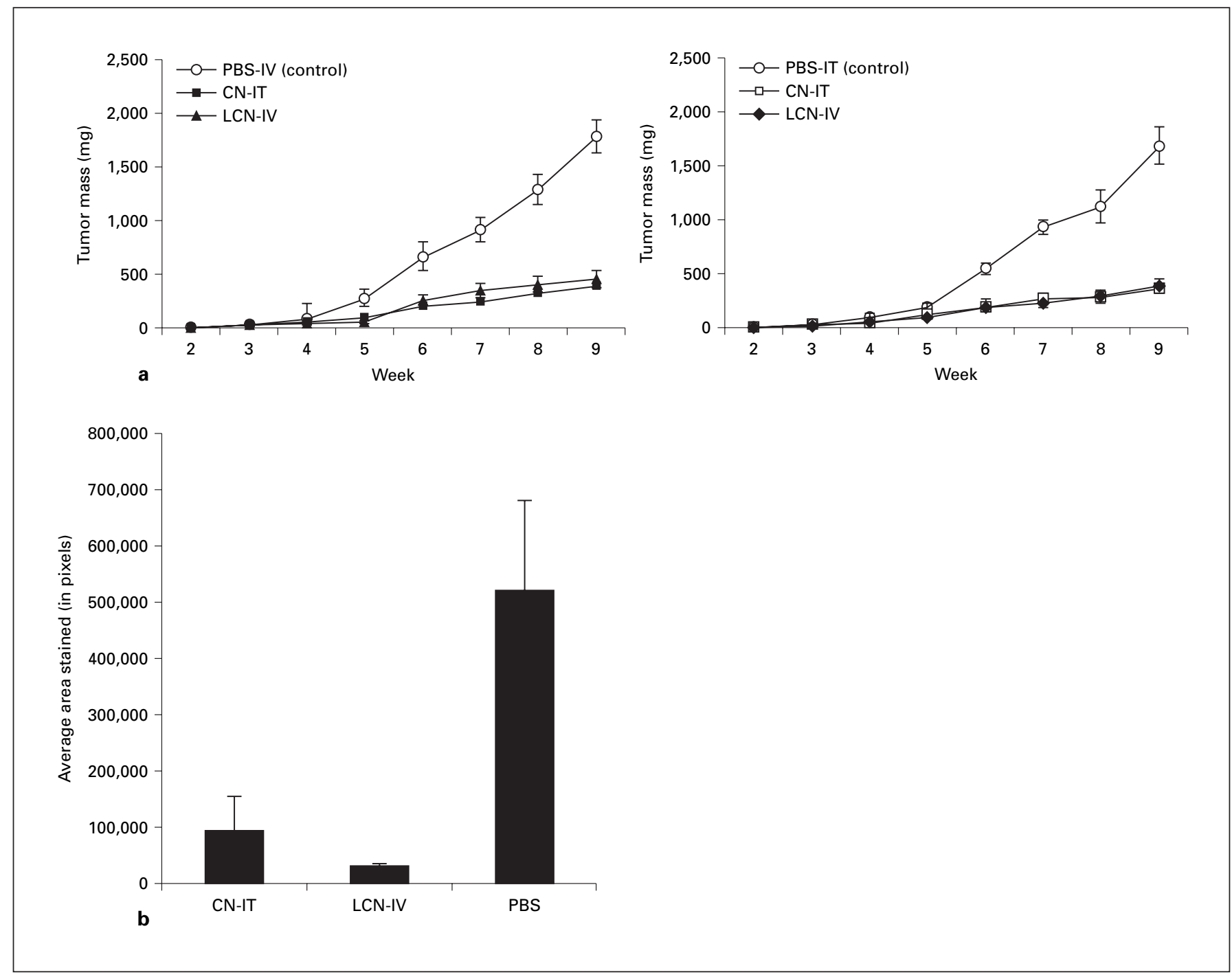

Fig. 1. Inhibition of MDA-MB-435 tumor growth and angiogenesis by LCN. Human mammary tumors (MDA-MB-435) were established by implantation of $5 \times 10^{5}$ cells into the mammary fat pads of 5-week-old female nude mice. a Groups containing 5 mice were treated as described in Materials and Methods (left panel). In the right panel there are 10 mice per group. Tumor mass was determined as described in Materials and Methods following weekly measurement with a caliper. LCN was statistically as effective as daily intratumor $\mathrm{CN}$ delivery when both were compared to control $(p<0.0001)$. Thus, intravenous administration of LCN is an effec-

lected from each organ in all animals and immediately fixed in formalin solution and processed for immunohistochemistry analysis using the neovessel marker CD31 to determine the amount of angiogenesis. tive means of limiting tumor growth in the orthotopic, xenograft model of human breast cancer. Data shown represent the geometric mean of the tumor sizes. Error bars are $95 \%$ confidence intervals. b Positive staining areas on CD31-immunostained slides were quantitated in terms of pixels with SimplePCI advanced imaging software. Ten animals were used per group and the data represents 10 areas from three sections from each mouse, the average area in pixels of CD31-stained vessels in each treatment group is presented $( \pm$ SD). CN-IT group shows $82 \%$ inhibition, while LCN-IV shows 94\% inhibition of angiogenesis, compared to PBS control.

\section{Contortrostatin Inhibits Tumor Burden as}

Determined by SEAP Activity

Each of the $40 \mathrm{~A} 2780^{\text {SEAP }}$ tumor-bearing animals were bled twice weekly; plasma was prepared from whole blood and stored at $-20^{\circ} \mathrm{C}$ until SEAP assay was performed. To 
Fig. 2. Effect of $C N$ on blood SEAP levels and angiogenesis in nude mice harboring A2780 ${ }^{\text {SEAP }}$ human ovarian cancer. a Blood SEAP levels (geometric mean \pm standard deviation) in the blood of control, and CNtreated groups are shown. There were no statistically significant differences in the SEAP levels (at days 5 and 8) between the four groups, but there were statistically significant differences in SEAP levels between control and the LCN-treated groups after day 12 . In addition, there is a statistically significant difference between control and CN-IP-treated group at days 19 and 22 (overall $\mathrm{p}=0.0002$ ). CN-IP $(\mathbf{\Delta})$-, LCN-IV Low (O)-, LCN-IV High (ם)-treated animals inhibit tumor burden by 14,44 , and $43 \%$, respectively, as compared to the PBS control group ( $\square$ ). See Materials and Methods for details. b CN was delivered intravenously at two doses, twice weekly $(105 \mu \mathrm{g}$ CN , LCN-IV, and $210 \mu \mathrm{g}$ LCN-IV High). All methods of $\mathrm{CN}$ administrations showed potent inhibition of angiogenesis in the tumor sections as compared to PBS control tumors. Positive staining areas on CD31stained slides were quantitated in terms of pixels with SimplePCI advanced imaging software. The CN-IP and LCN-IV-Low groups show $\sim 63 \%$ inhibition, while the LCN-IV-High group shows $\sim 87 \%$ inhibition of tumor-induced angiogenesis as compared to PBS-treated animals. The average area in pixels of CD31-immunostained vessels in each treatment group is presented ( $\pm \mathrm{SD})$.

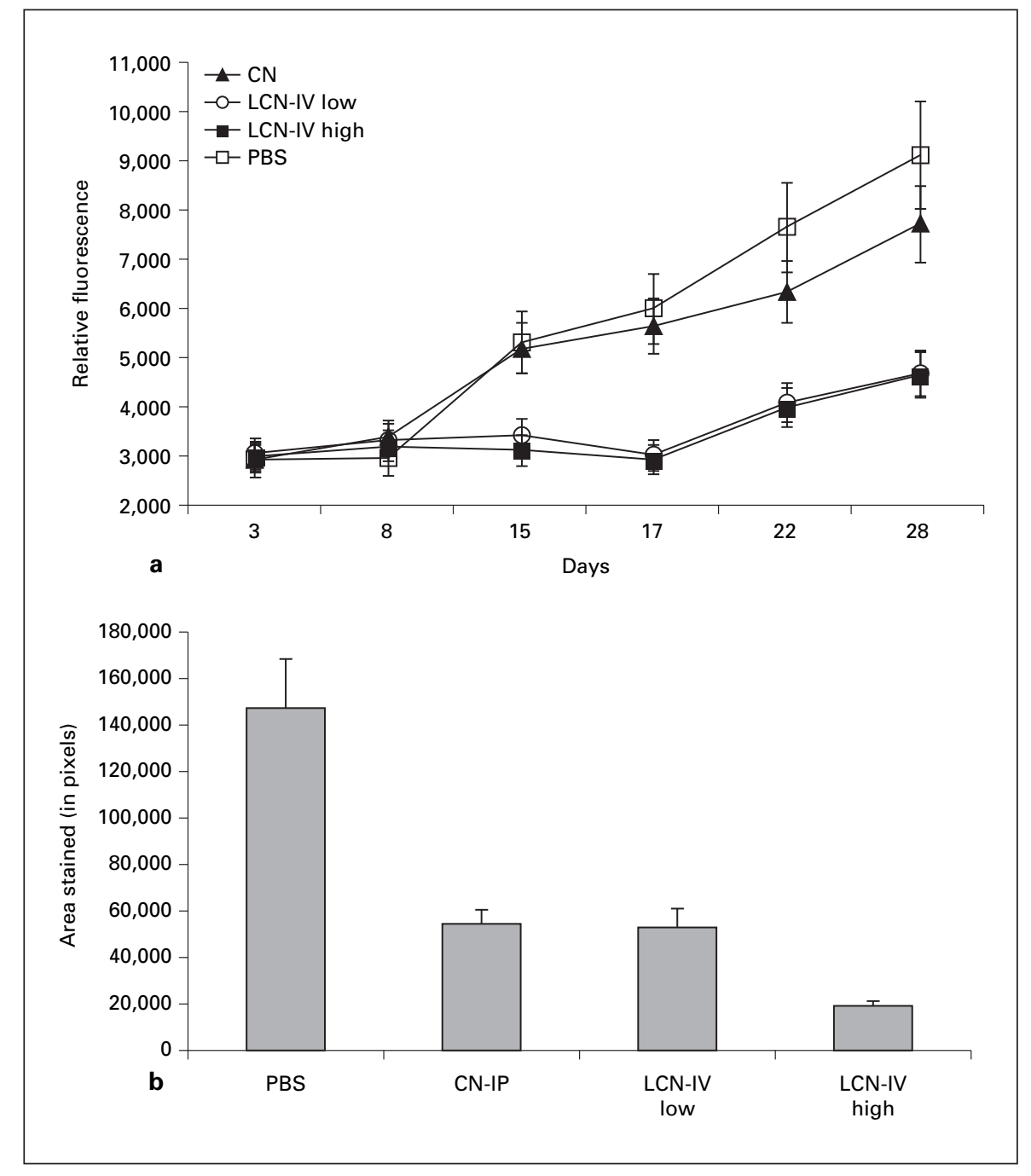

approximate the relative tumor burden for each treatment group a graph of SEAP activity (fluorescence intensity) as a function of collection day was prepared (fig. 2a). A difference in relative SEAP activity cannot be seen in control and treatment groups until day 12, similar to previous reports [18]. As expected, all the treated groups had lower SEAP values as compared to the control. However, the pattern was different than expected. We anticipated a dose-dependent decrease in tumor burden with increased dose of $\mathrm{CN}$; however, this was not what we observed. Daily IP injection of CN showed only 14\% decrease in SEAP activity as compared to control, while LCN-IV Low and High showed 44 and 43\% decrease, respectively. Over a 3-fold decrease in SEAP values was observed when comparing IP and IV delivery routes for
CN. A dose-dependent response was expected because it had been previously established that circulatory SEAP levels are directly proportional to tumor size [18].

\section{Quantitation of Positive CD31 Staining in A2780SEAP Tumor Sections}

To quantitate the anti-angiogenic effect of $\mathrm{CN}$, three 'hot spots' from each CD31 stained tumor were digitally captured as previously described [16]. The software assigns a pixel value for positive CD31 staining, and the average of all the pixels in all the tumors found in each treatment group is shown as a bar graph (fig. 2b). CN-IP and the low dose of LCN-IV inhibited angiogenesis by 62 and $63 \%$, respectively. This is not surprising since the weekly dosage for both groups is 
equivalent (210 $\mu \mathrm{g} \mathrm{CN/week),} \mathrm{although} \mathrm{the} \mathrm{modes} \mathrm{of}$ delivery are different. On the other hand, the high dose of LCN-IV (420 $\mu \mathrm{g} \mathrm{CN/week)} \mathrm{inhibited} \mathrm{angiogenesis} \mathrm{by}$ $87 \%$. Our findings indicate that twice weekly intravenous delivery of liposomal $\mathrm{CN}$ appears to be as effective as daily intraperitoneal injections at equivalent dosages. In addition, there is a significant increase in inhibition of angiogenesis when the weekly dose is doubled, thus implying a dose-dependent inhibition. Finally, twice weekly IV injections are a more clinically relevant mode of delivery than daily IP injections, and they are equally as effective.

\section{Discussion}

It has long been established that angiogenesis is necessary for tumor growth and dissemination [26, 27]. Kim et al. showed that a monoclonal antibody against vascular endothelial growth factor blocked the growth of human tumors transplanted into mice [29]; this was the first conclusive in vivo evidence that anti-angiogenic therapy inhibited tumor growth $[9,30]$. Angiogenesis appears to be an early event in epithelial ovarian cancer [31] and proangiogenic molecules are secreted by ovarian cancer cells to promote peritoneal dissemination [32]. There are a number of anti-angiogenic drugs currently in clinical trials [30], and a combination of anti-angiogenic treatments seems to have an additive effect in the inhibition of tumor growth [33]. Recently, the FDA has approved the first anti-angiogenic drug Avastin, a monoclonal antibody against VEGF, for cancer treatment. Ultimately, anti-angiogenic therapy should provide an additional cancer treatment suitable for combination with standard therapies [34].

Previous animal studies have shown that native ${ }^{125} \mathrm{I}-\mathrm{CN}$ administered intravenously has a circulatory half-life of only $0.5 \mathrm{~h}$ [16]. To overcome this problem, $\mathrm{CN}$ was encapsulated in liposomes. Intravenously injected L- ${ }^{125}$ I-CN has a circulatory half-life of $19 \mathrm{~h}$ [16]. Intravenous delivery of LCN is a more clinically relevant method of administration than intratumor delivery and twice weekly IV delivery of LCN displays anti-tumor and anti-angiogenic activity as effective as daily IT administration.

To assess in vivo biological activity of $\mathrm{CN}$, the MDAMB-435 breast cancer nude mouse model was initially employed. Breast cancer grows at the primary site as a solid tumor; this provides a distinct advantage over the ovarian cancer mouse model in which the tumors dis- seminate throughout the peritoneal cavity, making it difficult to quantitatively assess tumor burden. In the mammary tumor model, when the tumors are palpable (at 2 weeks) IV injection of LCN was initiated and continued for 6 weeks; weekly measurements of tumor mass were recorded and plotted. In the ovarian cancer model, LCN was administered intravenously for 4 weeks. A significant decrease of tumor mass in both $\mathrm{CN}$ - and LCNtreated groups in breast and ovarian cancer models were observed, although quantitation in the ovarian cancer model was not satisfactory.

Immunogenicity of intravenously administered LCN is of concern. However, in long-term (10 weeks) studies, we have seen no immune responses. Immunocompetent mice were intravenously injected with $\mathrm{CN}$ or LCN twice weekly, in the presence or absence of Freund's adjuvant (administered subcutaneously), and bled at the beginning of the experiment and then several times during it to analyze the presence of specific neutralizing anti-CN antibodies by ELISA. Only native $\mathrm{CN}$ in the presence of Freund's adjuvant (forced immune response) was found to be weakly immunogenic, but the LCN group, even in the presence of adjuvant, was not immunogenic [16]. These results, plus findings from previous in vitro and in vivo studies, suggest that IV administration of LCN will be suitable for long-term use in a clinical setting.

The dramatically increased circulatory half-life of LCN over native $\mathrm{CN}$ accounts for the accumulation of LCN at the tumor site due to the increased number of passes of LCN through the tumor. This leads to passive accumulation of LCN at the tumor due to the 'leakiness' of the angiogenic vasculature of the tumor [35]. Previous reports have shown that tumor vasculature lacks hierarchy, is structurally heterogeneous, and hyper-permeable to plasma proteins [36]. The hyper-permeability or 'leakiness' may be caused by the lack of pericytes in some tumor vasculature [37, 38]. Previous reports have shown that newly growing vasculature at the site of tumors is not intact $[9,28]$. The size of liposomes with encapsulated $\mathrm{CN}$ is approximately $140-170 \mathrm{~nm}$, and the liposomes are able to leak out of the newly growing angiogenic vessels, which supply blood to the tumor. Once the liposomes exit the 'leaky' vessels and form depots, lipases and other extracellular enzymes presumably aid in the slow degradation of liposomes releasing the entrapped protein [40].

The current study with the ovarian cancer cell line A2780 $0^{\text {EAP }}$ indicates that, as with the MDA-MD-435 breast tumor model, we have developed an effective and more clinically relevant method of delivery, liposomal encapsulation of CN (LCN). LCN shows significant effi- 
cacy in inhibiting tumor dissemination and angiogenesis in an $\alpha v \beta 3$ - negative, $\alpha v \beta 5$ - and $\alpha 5 \beta 1$-positive human ovarian cancer cell line following intravenous administration. In the study, LCN was delivered IV twice weekly while native $\mathrm{CN}$ was delivered IP daily. Both forms of treatment (at equivalent doses) showed a significant decrease in tumor growth and angiogenesis. However, IV administration of LCN allowed for a high level of tumor uptake and dose-dependent efficacy was observed. Therefore, as in the breast cancer model, twice weekly IV administration of LCN was a more effective method of de- livery than daily IP introduction of native $\mathrm{CN}$, both in limiting ovarian cancer dissemination and in inhibiting tumor angiogenesis. Thus, liposomal delivery of $\mathrm{CN}$ represents a clinically relevant method of administration.

\section{Acknowledgements}

This work was supported in part by funding from NIH (Grant 1 R41 CA96368) to F.S.M., and funding from the Susan G. Komen Breast Cancer Foundation (Grant BCTR0402574) to F.S.M.

\section{References}

1 Cheresh DA: Structural and biologic properties of integrin-mediated cell adhesion. Clin Lab Med 1992;12:217-236.

-2 Hynes RO: Integrins: versatility, modulation, and signaling in cell adhesion. Cell 1992;69: $11-25$.

3 Ruoslahti E: Integrins. J Clin Invest 1991;87: $1-5$.

4 Brooks PC, Clark RA, Cheresh DA: Requirement of vascular integrin alpha $\mathrm{v}$ beta 3 for angiogenesis. Science 1994;264:569-571.

-5 Brooks PC, Stromblad S, Klemke R, Visscher D, Sarkar FH, Cheresh DA: Antiintegrin alpha $\mathrm{v}$ beta 3 blocks human breast cancer growth and angiogenesis in human skin. J Clin Invest 1995; $96: 1815-1822$.

-6 Felding-Habermann B, O'Toole TE, Smith JW, Fransvea E, Ruggeri ZM, Ginsberg MH, Hughes PE, Pampori N, Shattil SJ, Saven A, Mueller BM: Integrin activation controls metastasis in human breast cancer. Proc Natl Acad Sci USA 2001;98:1853-1858.

7 Huang TF, Holt JC, Kirby ER, Niewiarowski S: Trigramin: primary structure and its inhibition of von Willebrand factor binding to glycoprotein IIb-IIIa complex on human platelets. Biochemistry 1989;28:661-666.

8 McLane MA, Marcinkiewicz C, Vijay-Kumar S, Wierzbicka-Patynowski I, Niewiarowski S: Viper venom disintegrins and related molecules. Proc Soc Exp Biol Med 1998;219:109_ 119.

-9 Adler M, Lazarus RA, Dennis MS, Wagner G: Solution structure of kistrin, a potent platelet aggregation inhibitor and GP IIb-IIIa antagonist. Science 1991;253:445-448.

-10 Trikha M, Rote WE, Manley PJ, Lucchesi BR, Markland FS: Purification and characterization of platelet aggregation inhibitors from snake venoms. Thromb Res 1994;73:39-52.

11 Zhou Q, Hu P, Ritter MR, Swenson SD, Argounova S, Epstein AL, Markland FS: Molecular cloning and functional expression of contortrostatin, a homodimeric disintegrin from southern copperhead snake venom. Arch Biochem Biophys 2000;375:278-288.
12 Trikha M, De Clerck YA, Markland FS: Contortrostatin, a snake venom disintegrin, inhibits beta 1 integrin-mediated human metastatic melanoma cell adhesion and blocks experimental metastasis. Cancer Res 1994;54:49934998.

13 Zhou Q, Nakada MT, Brooks PC, Swenson SD, Ritter MR, Argounova S, Arnold CA, Markland FS: Contortrostatin, a homodimeric disintegrin, binds to integrin avb5. Biochem Biophys Res Commun 2000;267:350-355.

14 Friedlander M, Brooks PC, Shaffer RW, Kincaid CM, Varner JA, Cheresh DA: Definition of two angiogenic pathways by distinct alpha y integrins. Science 1995;270:1500-1502.

15 Fujii G, Chang JE, Coley T, Steere B: The formation of amphotericin B ion channels in lipid bilayers. Biochemistry 1997;36:4959-4968.

16 Swenson S, Costa F, Minea R, Sherwin RP, Ernst W, Fujii G, Yang D, Markland FS Jr: Intravenous liposomal delivery of the snake venom disintegrin contortrostatin limits breast cancer progression. Mol Cancer Ther 2004;3 499-511.

17 Zhou Q, Sherwin RP, Parrish C, Richters V, Groshen SG, Tsao-Wei D, Markland FS: Contortrostatin, a dimeric disintegrin from Agkistrodon contortrix contortrix, inhibits breast cancer progression. Breast Cancer Res Treat 2000;61:249-260.

18 Bao R, Selvakumaran M, Hamilton TC: Use of a surrogate marker (human secreted alkaline phosphatase) to monitor in vivo tumor growth and anticancer drug efficacy in ovarian cancer xenografts. Gynecol Oncol 2000;78:373-379.

19 Zhou Q, Nakada MT, Arnold C, Markland FS: Contortrostatin, a dimeric disintegrin from Agkistrodon contortrix contortrix, inhibits angiogenesis. Angiogenesis 1999;3:259-269.

20 Markland FS, Shieh K, Zhou Q, Golubkov V, Sherwin RP, Richters V, Sposto R: A novel snake venom disintegrin that inhibits human ovarian cancer dissemination and angiogenesis in an orthotopic nude mouse model. Haemostasis 2001;31:183-191.
21 Golubkov V, Hawes D, Markland FS: Antiangiogenic activity of contortrostatin, a disintegrin from Agkistrodon contortrix contortrix snake venom. Angiogenesis 2003;6:213-224.

-22 Shi SR, Key ME, Kalra KL: Antigen retrieval in formalin-fixed, paraffin-embedded tissues: an enhancement method for immunohistochemical staining based on microwave oven heating of tissue sections. J Histochem Cytochem 1991;39:741-748.

23 Newman PJ: The role of PECAM-1 in vascular cell biology. Ann NY Acad Sci 1994; 714:165174.

24 Gasparini G, Weidner N, Maluta S, Pozza F, Boracchi P, Mezzetti M, Testolin A, Bevilacqua $\mathrm{P}$, Harris $\mathrm{AL}$ : Intratumoral microvessel density and $\mathrm{p} 53$ protein: correlation with metastasis in head-and-neck squamous-cell carcinoma. Evaluating the potential usefulness of new prognostic and predictive indicators in node-negative breast cancer patients. Int $\mathrm{J}$ Cancer 1993;55:739-744.

25 Weidner N, Folkman J, Pozza F, Bevilacqua P, Allred EN, Moore DH, Meli S, Gasparini G: Tumor angiogenesis: a new significant and independent prognostic indicator in early stage breast cancer. J Natl Cancer Inst 1992;84: 1875-1887.

26 Folkman J: Tumor angiogenesis: therapeutic implications. N Engl J Med 1971;285:11821186

27 Folkman J: Angiogenesis and breast cancer. J Clin Oncol 1994;12:441-443.

-28 Jain RK: Tumor angiogenesis and accessibility: role of vascular endothelial growth factor. Semin Oncol 2002;29:3-9.

-29 Kim KJ, Li B, Winer J, Armanini M, Gillett N, Phillips HS, Ferrara N: Inhibition of vascular endothelial growth factor-induced angiogenesis suppresses tumour growth in vivo. Nature 1993;362:841-844.

30 Marx J: Angiogenesis. A boost for tumor starvation. Science 2003;301:452-454. 
31 Nakanishi Y, Kodama J, Yoshinouchi M, Tokumo K, Kamimura S, Okuda H, Kudo T: The expression of vascular endothelial growth factor and transforming growth factor-beta associates with angiogenesis in epithelial ovarian cancer. Int J Gynecol Pathol 1997;16:256262.

32 Yabushita H, Shimazu M, Noguchi M, Kishida T, Narumiya H, Sawaguchi K: Vascular endothelial growth factor activating matrix metalloproteinase in ascitic fluid during peritoneal dissemination of ovarian cancer. Oncol Rep 2003;10:89-95.
3 Bergers G, Song S, Meyer-Morse N, Bergsland E, Hanahan D: Benefits of targeting both pericytes and endothelial cells in the tumor vasculature with kinase inhibitors. J Clin Invest 2003;111:1287-1295.

34 Kerbel RS, Klement G, Pritchard KI, Kamen B: Continuous low-dose anti-angiogenic/metronomic chemotherapy: from the research laboratory into the oncology clinic. Ann Oncol 2002;13:12-15.

35 Dvorak HF: Leaky tumor vessels: consequences for tumor stroma generation and for solid tumor therapy. Prog Clin Biol Res 1990; 354A:317-330.

36 Dvorak HF: Rous-Whipple Award Lecture. How tumors make bad blood vessels and stroma. Am J Pathol 2003;162:1747-1757.
37 Dvorak HF, Nagy JA, Dvorak JT, Dvorak AM: Identification and characterization of the blood vessels of solid tumors that are leaky to circulating macromolecules. Am J Pathol 1988;133:95-109.

38 Ruoslahti E: Specialization of tumor vasculature. Nat Rev Cancer 2002;2:83-90.

39 Hashizume H, Baluk P, Morikawa S, McLean JW, Thurston G, Roberge S, Jain RK, McDonald DM: Openings between defective endothelial cells explain tumor vessel leakiness. Am J Pathol 2000; 156:1363-1380.

40 Brown JM, Giaccia AJ: The unique physiology of solid tumors: opportunities (and problems) for cancer therapy. Cancer Res 1998;58:14081416. 